\title{
RANCANG BANGUN APLIKASI DETEKSI KEASLIAN FILE AUDIO MENERAPKAN METODE CRC 32
}

\author{
Dian Paramita Br Perangin-angin
}

\author{
Program Studi Teknik Informatika STMIK Budi Darma, Medan, Indonesia \\ Email: dianparamita130@gmail.com
}

\begin{abstract}
Abstrak
Keaslian sebuah file digital adalah sesuatu hal yang harus bisa dapat dijamin keberadaannya, mengingat begitu banyak perangkatperangkat yang dapat digunakan untuk melakukan tindakan pemanipulasia terhadap file digital tersebut. Salah satu file digital yang dibahas dalam penelitian ini adalah file audio dengan ekstensi file MP3. Perlu diketahui file audio MP3 saat ini sangat mudah didapatkan bahkan sangat mudah dimanipulasi dan disisipkan objek didalamnya sehingga diperlukan sebuah teknik pengamanaan untuk menjaga keaslian file audio tersebut. Mengatasi masalah tersebut yang telah dijelaskan pada paragraf sebelumnya maka teknik pengamanan yang tepat digunakan adalah teknik kriptografi hash, dengan menerapkan algoritma CRC 32 . Penerapan CRC 32 bertujuan untuk menghasilkan kode hash dari file audio MP3 yang dapat digunakan sebagai kode kunci (key) untuk autentikasi (keaslian) dari file audio MP3. Hasil dari penelitian ini adalah representasi tentang penjelasan teknik penerapan algoritma CRC 32 dalam menghasilkan kode hash file audio MP3, yang mana algoritma CRC 32 tersebut diterapkan pada aplikasi yang telah dirancang dan dibangun dengan menggunakan bantuan perangkat lunak MATLAB versi 6.1.
\end{abstract}

Kata kunci: Keaslian File, File Audio, CRC 32, MATLAB 6.1

\begin{abstract}
The authenticity of a digital file is something that must be able to be guaranteed its existence, considering that there are so many devices that can be used to carry out manipulation of the digital file. One of the digital files discussed in this study is an audio file with MP3 file extension. Please note that MP3 audio files are now very easy to obtain, even very easy to manipulate and insert objects in, so we need a safety technique to maintain the authenticity of the audio file. Overcoming the problem that has been explained in the previous paragraph, the appropriate security technique used is the hash cryptographic technique, by applying the CRC 32 algorithm. The application of CRC 32 aims to generate hash codes from MP3 audio files that can be used as key codes for authentication (key authenticity) of MP3 audio files. The results of this study are a representation of the technical explanation of the application of the CRC 32 algorithm in generating MP3 audio file hash codes, which the CRC 32 algorithm is applied to applications that have been designed and built using the help of MATLAB software version 6.1.
\end{abstract}

Keywords: File Authenticity, Audio File, CRC 32, MATLAB 6.1

\section{PENDAHULUAN}

File audio merupakan suatu bagian suara atau bunyi yang berisi data berbentuk gelombang. Sebagian besar, saat ini banyak yang mendengarkan musik dari pemutar musik digital, komputer dan handphone karena sangat mudah untuk didapat. Terdapat beberapa jenis format file audio yaitu WAV (WAV-Form), AAC (Advanced Audio Coding), MPEG Layer 3 (MP3) dan WMA (Windows Media Audio). Format file audio juga memiliki kelebihan maupun kekurangan masing-masing.

Dalam perkembangan file digital, file digital memiliki sifat yang mudah untuk dimodifikasi sehingga sering menimbulkan masalah keaslian kepemilikan informasi dalam file digital tersebut. Keaslian sebuah file digital adalah sesuatu hal yang harus bisa dapat dijamin keberadaannya, mengingat begitu banyak perangkat-perangkat yang dapat digunakan untuk melakukan tindakan manipulasi atau pembajakan terhadap file digital tersebut. Salah satu file digital yang dibahas dalam penelitian ini adalah file audio dengan format MP3. Perlu diketahui file audio MP3 saat ini sangat mudah didapatkan bahkan sangat mudah dimanipulasi dan disisipkan objek didalamnya sehingga diperlukan sebuah teknik pengamanaan untuk menjaga keaslian file audio tersebut.

Mengatasi masalah yang telah dijelaskan pada paragraf sebelumnya maka teknik pengamanan yang tepat digunakan adalah teknik kriptografi hash, dengan menerapkan algoritma CRC 32. Penerapan CRC 32 bertujuan untuk menghasilkan kode hash dari file audio MP3 yang dapat digunakan sebagai kode kunci (key) untuk keaslian (autentikasi) dari file audio MP3.

Kriptografi (cryptography) merupakan ilmu dan seni untuk menjaga pesan agar aman. (Cryptography is the art and science of keeping messages secure) "Crypto" berarti "secret" (rahasia) dan "graphy" berarti "writing" (tulisan). Jadi, kriptografi adalah ilmu dan seni untuk menjaga keamanan pesan yang akan dikirim ke penerima sehingga data atau pesan tersebut aman dan tidak diketahui oleh pihak ketiga[1]. Kekuatan suatu teknik kriptografi adalah pada kerumitan kunci dan algoritmanya, sehingga pesan ataupun file yang dikirimkan tidak mudah ditebak oleh orang lain sehingga data yang dikirimkan terjaga kerahasiaannya[2]. Ada berbagai macam jenis metode ataupun kriptografi yang sekarang ini telah ada dan sedang dikembangkan, namun yang dibahas pada penelitian ini adalah metode CRC 32 (Cyclic Redundancy Check 32 bit).

CRC 32 (Cyclic Redundancy Check 32 bit) merupakan suatu teknik yang menggunakan fungsi hash dalam membaca sebuah struktur dalam sebuah file dalam penyimpanan sebuah data. CRC 32 dapat digunakan untuk mendeteksi kerusakan (error) pada sebuah data yang mungkin terjadi pada saat transmisi data atau pengiriman data. 
Teknik ini menghitung nilai checksum dari panjang bit sebuah data yang kemudian membandingkannya dengan tabel CRC 32 untuk mendeteksi apakah data tersebut mengalami perubahan atau tidak [3].

Terdapat beberapa metode dalam mendeteksi keaslian suatu file, salah satunya adalah metode Cyclic Redundancy Check 32 (CRC 32), yang berguna untuk mendeteksi kerusakan file dan mendeteksi keaslian file. CRC memiliki beberapa varian bergantung pada bilangan polynominal yang digunakan dalam proses komputasinya. Meskipun CRC tidak cukup aman sebagai algoritma kriptografi, tetapi CRC cukup efektif digunakan karena CRC mudah diimplementasikan dalam hardware maupun software, dan cukup cepat dalam melakukan komputasinya. Untuk mempermudah proses komputasinya, maka diperlukan sebuah algoritma CRC 32.

\section{LANDASAN TEORI}

\subsection{Deteksi Keaslian}

Deteksi atau mendeteksi merupakan suatu proses untuk memeriksa atau menilai sesuatu seperti uang, file audio, file video dan dokumen dengan menggunakan suatu cara dan teknik tertentu. Keaslian adalah kata dasar dari asli, yang berarti tidak terjadi perubahan dan tidak adanya salinan ataupun campuran dari file lain.

Dapat didefinisikan bahwa deteksi keaslian merupakan suatu proses memeriksa sebuah file dengan menggunakan teknik tertentu agar tidak terjadi suatu perubahan ataupun salinan dalam sebuah file.

\subsection{File Audio}

Audio (Suara) dapat didefinisikan sebagai macam-macam bunyi dalam bentuk digital seperti suara, musik, narasi dan sebagainya yang bisa untuk suara latar. Tujuan audio juga untuk menyampaikan pesan duka, sedih, senang, ketakutan dan disesuaikan situasi dan kondisi. Dalam audio, multimedia dapat berbentuk narasi, lagu, dan sound effeck, narasi ditampilkan dengan teks atau foto untuk memperjelas informasi yang disampaikan. Jenis-jenis format audio sebagi berikut[8]:

1. Type file $=$.aiff (audio interchang file format)

2. Type file $=$.au dan .snd

3. $\quad$ Type file $=$.ra atau. $\mathrm{rm}$ (real audio)

4. Type file $=. \mathrm{mp} 3($ MPEG audio Layer 3$)$

5. Type file $=. \operatorname{mov}$ (Quicktime Movie)

6. Type file $=$.swa ( shockware Audio $)$

7. Type file $=. \operatorname{asf}($ Advance Streaming Format $)$

\subsection{Metode CRC 32}

CRC 32 (Cyclic Redundancy Check 32 Bit) merupakan suatu teknik yang menggunakan fungsi hash dalam membaca sebuah struktur dalam sebuah file dalam transmisi atau penyimpanan sebuah data. CRC 32 dapat digunakan untuk mendeteksi error (kerusakan) pada sebuah data yang mungkin terjadi pada saat transmisi data atau pengiriman data. Teknik ini menghitung nilai checksum dari panjang bit sebuah data yang kemudian membandingkannya dengan aturan CRC dengan menggunakan kunci 32 bit untuk mendeteksi apakah data tersebut mengalami perubahan atau tidak[10].

Prinsip kerja CRC adalah menganggap suatu file yang diproses sebagai suatu string yang besar dan terdiri dari bitbit. Kemudian operasikan suatu bilangan polynomiai (pernyataan yang terbentuk dari satu atau lebih variabel dan konstanta) yang sangat besar. Untuk menghitung nilai CRC, membagi bilangan polynomial sebagai representasi dari file, dengan suatu bilangan polynomial kecil yang sudah terdefinisi untuk CRC. Nilai CRC adalah sisa hasil bagi tersebut yang biasa disebut dengan checksum[3].

Dalam penghitungan $\mathrm{CRC}$, operasi pengurangan dan penjumlahan dilakukan dengan melakukan operasi XOR pada bit, jika operasi tersebut ekuivalen dengan operasi pengurangan pada aljabar biasa. Perhitungan CRC juga mengabaikan bit carry setelah bit tersebut melewati suatu operasi. Adapun proses penghitungan checksum pada CRC32 yaitu: Poly = 10011 (width $\mathrm{W}=4$ ) Bitstring $+\mathrm{W}$ zeros $=110101101+0000$ Contoh pembagian yang dilakukan:

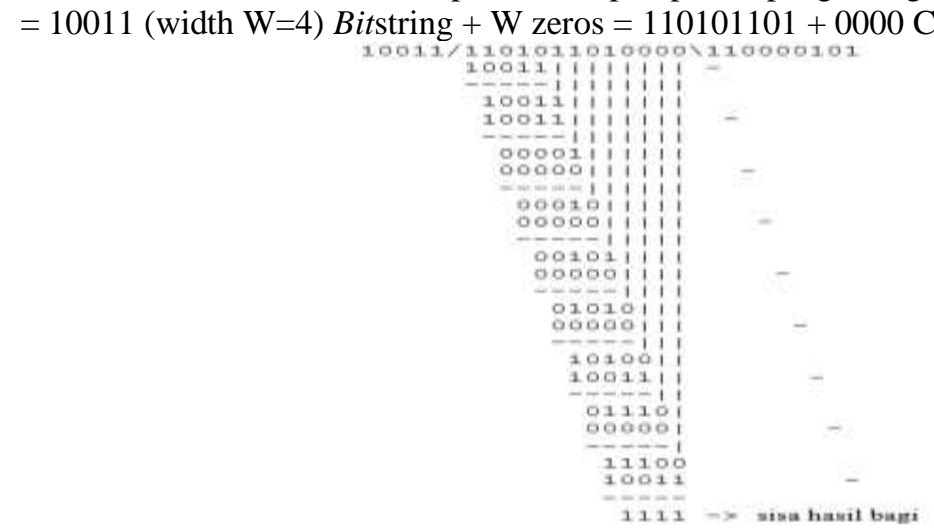

Gambar 1. Proses Perhitungan Cheksum CRC 32 
Nilai remainder inilah yang menjadi nilai CRC. Pada proses pembagian tersebut, kita mendapat hal penting yang perlu kita perhatikan dalam penghitungan secara aljabar ini adalah kita tidak perlu melakukan operasi XOR ketika bit tertinggi bernilai 0, tapi kita hanya melakukan penggeseran (shift) sampai didapat bit tertinggi yang bernilai 1 . Hal ini akan sedikit mempermudah dan mempercepat operasi aljabar kita.

Secara notasi aljabar bisa kita tuliskan sebagai berikut:

$\mathrm{a}(\mathrm{x}) \cdot \mathrm{xN}=\mathrm{b}(\mathrm{x}) \cdot \mathrm{p}(\mathrm{x})+\mathrm{r}(\mathrm{x})$

Keterangan: a (x) : Bilangan polynomial yang mempresentasikan data.

$\mathrm{xN}$ : Nilai 0 sebanyak $\mathrm{W}$

$\mathrm{b}(\mathrm{x})$ : Hasil bagi yang didapat

$\mathrm{p}(\mathrm{x})$ : poly $\mathrm{r}(\mathrm{x})$ : sisa hasil bagi, nilai CRC

Saat file dideteksi apakah mengalami perubahan atau tidak, maka yang dilakukan adalah[11]:

\section{ANALISA DAN PEMBAHASAN}

\subsection{Analisa Keaslian File Audio}

Analisa keaslian file audio adalah mendeteksi keaslian suatu file audio dengan melakukan proses pengecekan atau perbandingan suatu keaslian dari file audio asli dengan file audio yang telah dirubah. File audio merupakan sejenis file yang berupa suara ataupun berupa musik seperti MP3 yang dapat diakses. Dalam kejahatan biasanya file audio dimanipulasi dan hal ini dapat merugikan orang yang telah bersusah payah membuatnya. Oleh karena itu diperlukan analisa untuk mendeteksi keaslian file audio.

File audio memiliki sifat yang mudah diubah atau dimodifikasi, sehingga menimbulkan masalah keaslian kepemilikan dalam konten multimedia. Untuk mengetahui keaslian file audio dibutuhkan aplikasi MATLAB dan file yang akan dideteksi. Dalam mendeteksi keaslian file audio digunakan metode CRC 32, suatu teknik yang menggunakan fugsi hash. Agar dapat memudahkan saya, saya menggunakan software MATLAB untuk rancang bangun aplikasi deteksi keaslian file audio.

Adanya perubahan dari bentuk aslinya musik MP3 dapat diklasifikasikan sebagai tindakan sengaja atau tidak sengaja. Perubahan yang disengaja memiliki tujuan yang jahat dengan memodifikasikan konten atau menghapus hak cipta. Perubahan yang tidak disengaja merupakan konsekuensi dari proses operasional digital seperti perubahan format, dan pengurangan ukuran. Untuk membedakan file audio asli atau file audio yang sudah dirubah maka diperlukan pendeteksian file audio. Metode yang digunakan untuk mendeteksi file audio dengan deteksi yang hanya mengecek integritas dari file audio tanpa menunjukkan bagian mana pada file audio yang telah dimanipulasi. Namun tidak dapat memberikan informasi lokasi yang telah dimanipulasi pada file audio. Oleh karena itu maka diperlukan adanya pengecekan keaslian suatu file audio dengan memberikan suatu kode dari suatu file audio asli.

Untuk memudahkan analisa sistem maka dibuat bagan aliran analisa seperti pada gambar 2. dibawah ini.

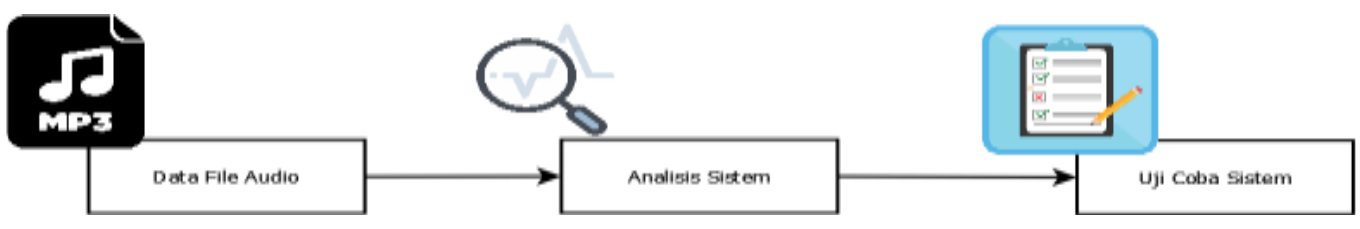

Gambar 2. Bagan Alir Analisa Mendeteksi Keaslian File audio

\subsubsection{Analisa Mendeteksi Keaslian File Audio Dengan Menerapkan Metode CRC 32}

Mendeteksi keaslian file audio dapat dilakukan dengan menggunakan metode CRC 32, untuk mendeteksi keaslian file audio dengan hanya mengecek integritas dari file audio tanpa menunjukkan bagian mana file audio yang telah dimanipulasi. Fungsi hash pada CRC 32 mempunyai proses masukan yang sama maka ia harus memberi hasil yang sama.

Jika dua objek sama, maka kode hasil perhitunganya juga sama. Adapun metode yang digunakan untuk mengecek keaslian file audio yaitu metode CRC 32 (Cyclic Redudancy Check 32). Untuk mendeteksi suatu keaslian file dengan CRC32 dapat dilakukan dengan:

1. Mengkonversi bilangan heksadesimal menjadi bilangan biner.

2. Melakukan XOR dengan FF.

3. Mengkonversi hasil dari XOR nilai biner dengan FF ke bilangan heksadesimal.

4. Setelah mendapat nilai heksadesimal maka mencari nilai dari tabel dari ketetapan metode CRC 32 .

5. Hasil dari tabel CRC 32 dikonversikan kedalam biner dan melakukan operasi XOR FF000000.

6. Nilai heksadesimal di XOR perbaris untuk mendapatkan nilai CRC 32. 


\section{IMPLEMENTASI}

Proses pengujian algoritma CRC 32 dalam aplikasi deteksi keaslian file audio MP3 yang dibangun menggunakan MATLAB, langkah pertama yang dilakukan adalah mengakses terlebih dahulu file audio yang akan diproses seperti pada gambar berikut ini:

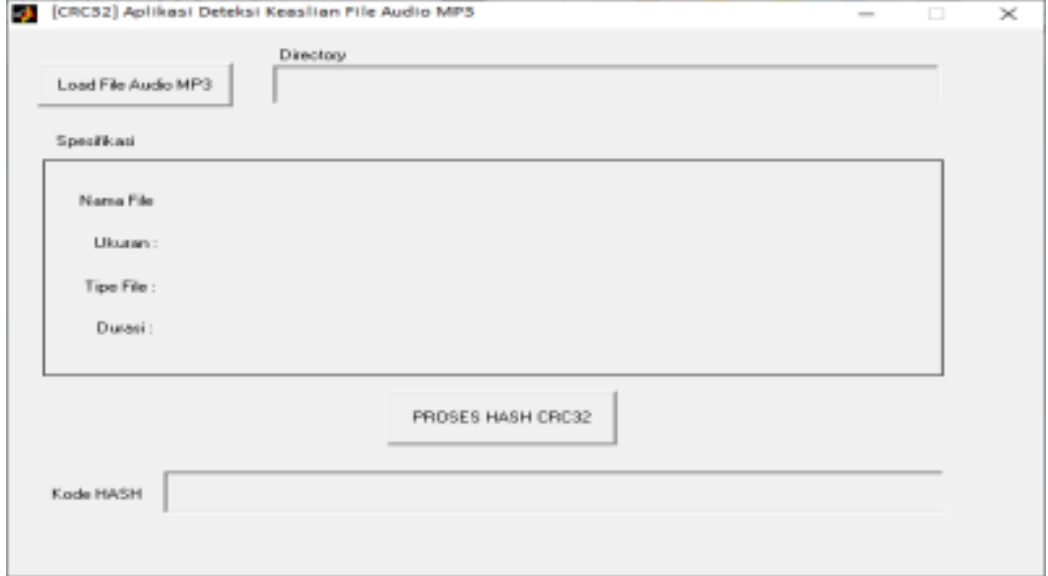

Gambar 3. Tampilan Form Aplikasi CRC32

Dari tampilan gambar diatas klik tombol "Load File Audio Mp3” untuk mengakses file audio di directory, seperti pada gambar berikut ini:

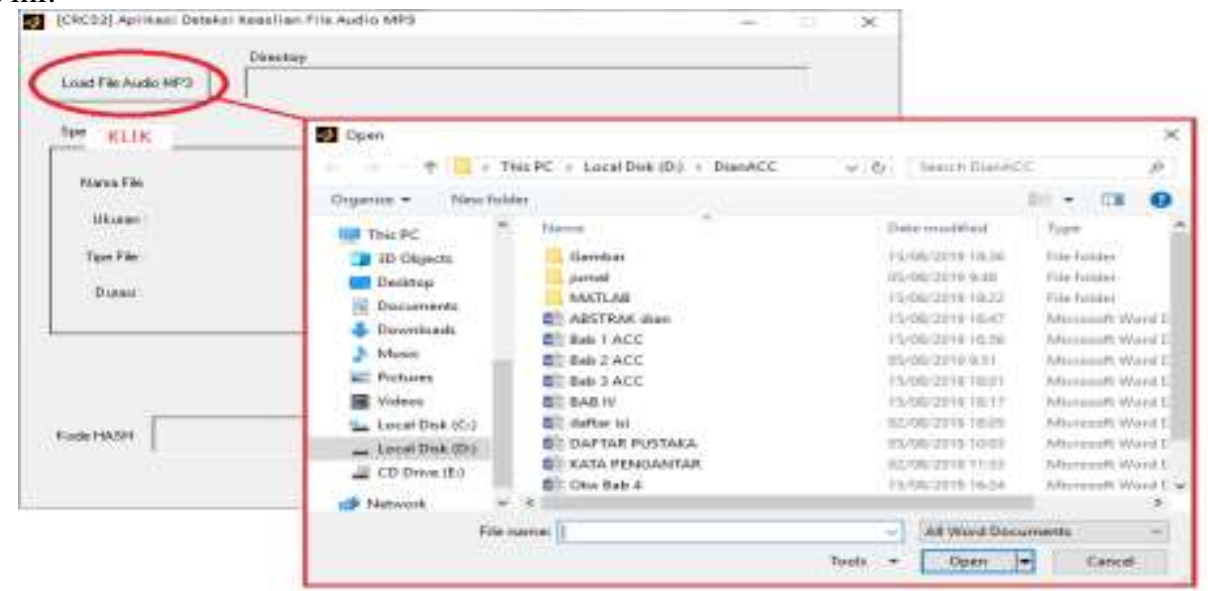

Gambar 4. Proses Akses File Audio MP3

Setelah ditemukan file audio yang diproses selanjutnya klik tombol open sehingga pada tampilan form aplikasi tampak seperti berikut ini:

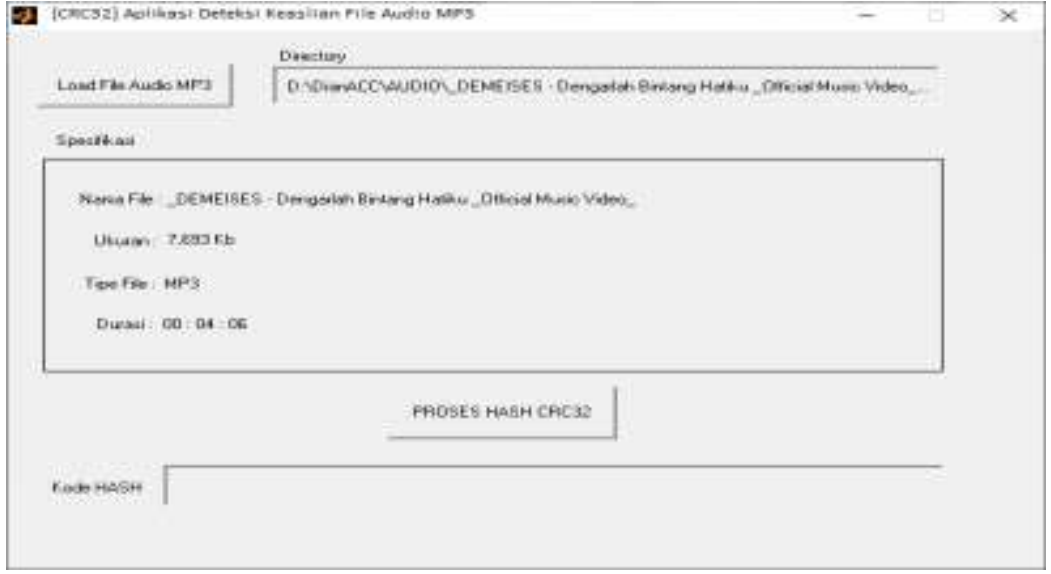

Gambar 5. Informasi Spesifikasi File Audio MP3

Selanjutnya klik tombol Proses HASH CRC 32 maka tampil nilai hash dari pada file audio MP3 seperti pada gambar berikut ini 


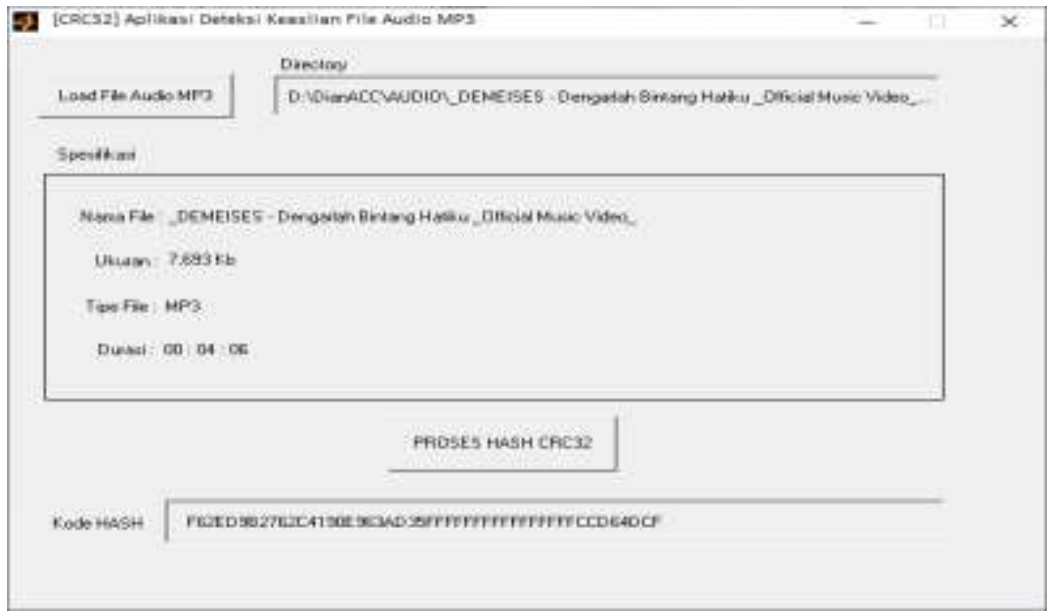

Gambar 6. Proses Hash CRC 32

\section{KESIMPULAN}

Dari skripsi yang telah saya buat dapat disimpulkan bahwa:

1. Teknik yang dilakukan untuk mendeteksi keaslian file audio adalah dengan menggunakan algoritma CRC 32 untuk mencari nilai hash yang ada pada file audio MP3 yang akan dideteksi.

2. Dalam menerapkan metode CRC 32 yang diperlukan adalah file audio dengan format MP3 dengan matriks 6 x 6 yang diambil dari frame file audio dari aplikasi binary viewer, aplikasi binary viewer adalah aplikasi untuk membantu penulis dalam mengubah sebuah file menjadi bilangan biner dan heksadesimal.

3. Aplikasi deteksi keaslian file audio dibangun dan dirancang dengan aplikasi MATLAB versi 6.1.

\section{REFERENCES}

[1] Sumandri, "Studi Model Algoritma Kriptografi Klasik dan Modern,” Semin. Mat. dan Pendidik. Mat. UNY, pp. 265-272, 2017.

[2] Suhardi, “Aplikasi Kriptografi Data Sederhana Dengan Metode Exlusive-or ( Xor ),” vol. 03, pp. 23-31, 2016.

[3] N. Fitrokhoerani and A. Anggraeni, "Penggunaan Metode Heuristik Dan Cyclic Redudancy Check 32 ( CRC32) Untuk Mendeteksi Kerusakan File," vol. 32, pp. 77-84, 2016.

[4] Zulfiandri, "Rancang bangun aplikasi poliklinik gigi (studi kasus : poliklinik gigi kejaksaan agung ri)," Univ. Gunadarma, vol. 8, no. Kommit, pp. 473-482, 2014

[5] Juansyah Andi, "PEMBANGUNAN APLIKASI CHILD TRACKER BERBASIS ASSISTED - GLOBAL POSITIONING SYSTEM ( A-GPS ) DENGAN PLATFORM ANDROID Jurnal Ilmiah Komputer dan Informatika ( KOMPUTA ),” J. Ilm. Komput. dan Inform., vol. 1, no. 1, pp. 1-8, 2015.

[6] S. Yulianto and B. Wijaya, "Aplikasi M-Commerce Berbasis Android Pada Phone Comp Service," J. Sisfokom (Sistem Inf. dan Komputer), vol. 3, no. 2, p. 57, 2014

[7] A. Widarma and S. Rahayu, "PERANCANGAN APLIKASI GAJI KARYAWAN PADA PT . PP LONDON SUMATRA INDONESIA Tbk . GUNUNG MALAYU ESTATE - KABUPATEN ASAHAN E-ISSN 2615-2738,” vol. 1, no. 2, pp. 168 179, 2017.

[8] Kausar, Ahmad, Y.F. Sutiawan, and V. Rosalina, "Perancangan Video Company Profile Kota Serang Dengan Teknik Editing Menggunakan Adobe Premier Pro CS 5," J. PROSISKO Vol.2 No. 1 Maret 2015, vol. 2, no. 1, pp. 22-30, 2015.

[9] S. T. Wahyudi, E. Safrianti, and Y. Rahayu, "Aplikasi Spectrum Analyzer Untuk Menganalisa Frekuensi Sinyal Audio Menggunakan Matlab,” $J$. 